University of Nebraska - Lincoln

DigitalCommons@University of Nebraska - Lincoln

Alan Bond Publications

Papers in the Biological Sciences

2001

The Evolution of Virtual Ecology

Alan Kamil

University of Nebraska - Lincoln, akamil1@unl.edu

Alan B. Bond

University of Nebraska - Lincoln, abond1@unl.edu

Follow this and additional works at: https://digitalcommons.unl.edu/bioscibond

Part of the Behavior and Ethology Commons

Kamil, Alan and Bond, Alan B., "The Evolution of Virtual Ecology" (2001). Alan Bond Publications. 7.

https://digitalcommons.unl.edu/bioscibond/7

This Article is brought to you for free and open access by the Papers in the Biological Sciences at DigitalCommons@University of Nebraska - Lincoln. It has been accepted for inclusion in Alan Bond Publications by an authorized administrator of DigitalCommons@University of Nebraska - Lincoln. 

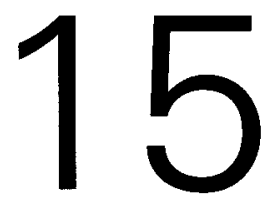

\title{
The Evolution of Virtual Ecology
}

\author{
Alan C. Kamil and Alan B. Bond
}

The relationship between the perceptual and cognitive abilities of predatory birds and the appearance of their insect prey has long been of intense interest to evolutionary biologists. One classic example is crypsis, the correspondence between the appearance of prey species and of the substrates on which they rest which has long been considered a prime illustration of effects of natural selection, in this case operating against individuals that were more readily detected by predators (Poulton 1890; Wallace 1891). But the influences of predator psychology are broader, more complex, and more subtle than just pattern matching. Many cryptic prey, including the underwing moths (Catocala) that rest against tree bark in the daytime, are also polymorphic. This discontinuous variation in appearance is thought to make prey harder to find initially and harder to detect even after the predator has learned of their appearance (Poulton 1890).

In contrast to cryptic prey, other prey appear to have taken the opposite route, being quite conspicuous in appearance. The aposematic or warning coloration displayed by many distasteful or poisonous species appears to facilitate avoidance learning by predators (Guilford 1990; Schuler \& Roper 1992). Batesian mimicry (Bates 1862), in which palatable prey evolve to imitate the appearance of aposematic species, appears to take advantage of the predator's tendency to stimulus generalization (Oaten et al. 1975). Even a century after many of these ideas were first proposed, however, much of the work in this area is still based on correlational data or on experiments that bear only indirectly on the issue.

The reason lies in part in the intractable nature of hypotheses about behavioral evolution. Behavior lacks a substantive fossil record, which means that any account of its origins must necessarily be inferential. Worse, behavioral evolution usually involves a dynamic interplay between the behavior and the environment that is difficult to reconstruct adequately under controlled conditions. As a result, even inferential investigations of the phenomenon generally bear only indirectly on the conditions under which the behavior actually evolved. To circumvent this constraint, we have developed an experimental method that allows realistic, repeatable simulation of the original processes involved in the evolution of color patterns in prey organisms. This "virtual ecology" technique provides an innovative approach to the experimental study of evolutionary dynamics and a quantum improvement in the ability to test evolutionary hypotheses. Our purpose in this chapter is to describe the development of the virtual ecology technique as the product of the cross- 
fertilization of ideas from a variety of disciplines, including operant psychology, behavioral ecology, population dynamics, and evolutionary computer algorithms. We have chosen to do this in a personal, autobiographical way in an attempt to communicate the flavor of what it has actually been like to experience these developments. In order to be historically accurate, we needed to emphasize the roles of coincidence and happenstance as well as of knowledge and synthesis in this process. We hope that the chapter will be fun to read and that it will provide useful insight into one example of how scientific research actually takes place.

\section{The Original Problem}

Traditionally, psychologists have studied the sensory and cognitive capacities of animals in settings far removed from the natural world. Yet processes such as perception, attention, and memory are quite important in many natural systems, and the authors have long shared an interest in studying cognition within natural systems, in its original evolutionary context. One system that lends itself to this approach is the interaction between cryptic insects and predators that conduct a visual search for prey. The cognitive characteristics of such predators have influenced the evolution of both cryptic coloration and polymorphism, the occurrence of multiple cryptic forms of a single prey species. Cryptic polymorphic species are common in many groups of insects, particularly grasshoppers, leaf-hoppers, true bugs, and moths (Fig. 15.1).

The selective pressure for crypticity derives from the tendency of predators to feed most on prey that are easiest to find. To the degree that prey appearance is genetically based, one would expect selection to favor individuals that were harder to detect. Polymorphism as a response to predation is less obvious. A predator that has to hunt for several different prey types will, however, be less efficient than a predator that can search for just one. As a result, selection will promote the accumulation of novel color variants in these species. A new morph, arriving either through immigration or mutation, which differs sufficiently in appearance from prey with which the predators are already familiar should gain advantage, escaping predation long enough to become established as an element of the local population.

Even after establishment of a novel morph, cognitive features of the predators may continue to act on the prey population. If prey detection is frequency-dependent, in that more common prey types are more likely to be taken (what is often termed "apostatic selection"), then the prey population will tend to stabilize with relatively constant numbers of the different morphs. Apostatic selection may result from a number of different factors in the predator's behavior (Allen 1988), but the most interesting mechanism from a behavioral standpoint is hunting by searching image. Searching im- 


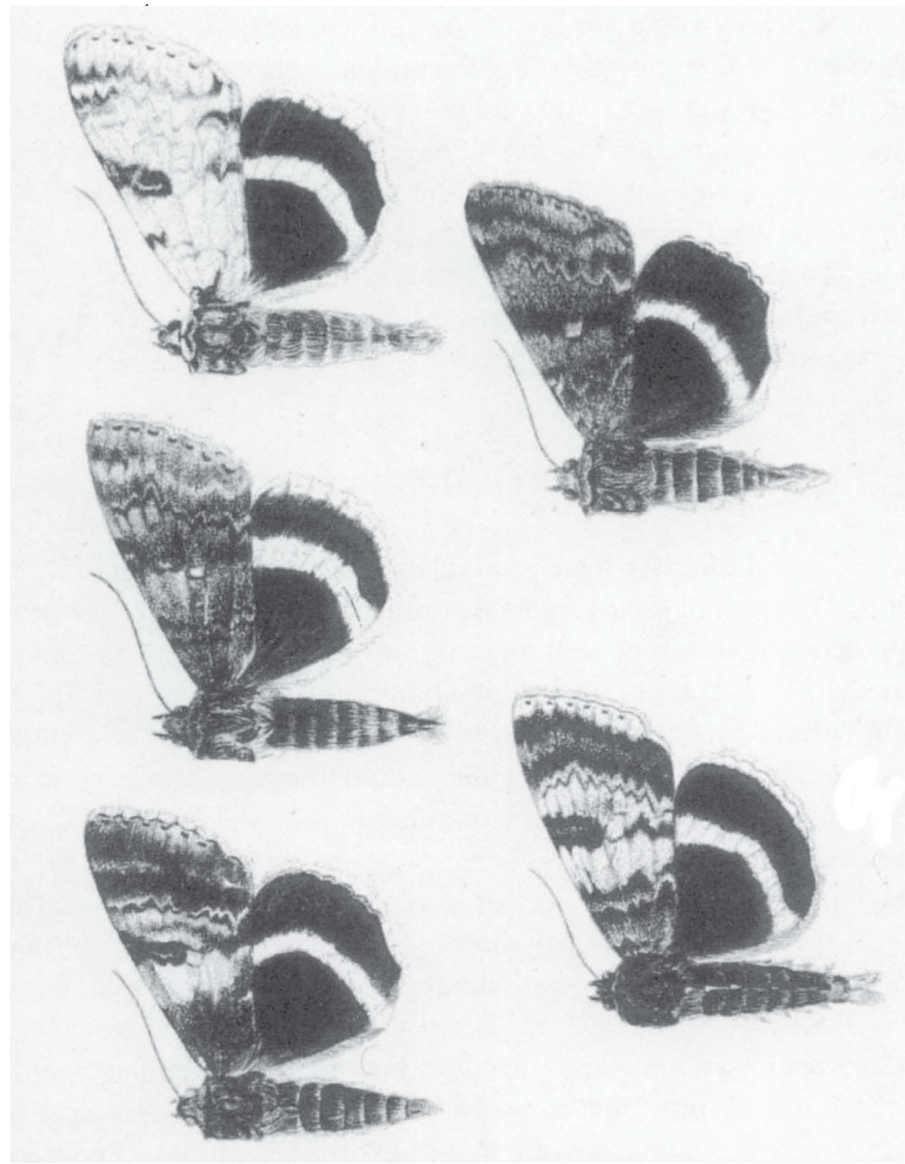

Figure 15.1. Five specimens of Catocala relicta, demonstrating their forewing polymorphism. Note the variation in the patterning and brightness of the forewing, which is the only part of the wing seen when the moth is at rest.

age was developed as an ecological hypothesis by L. Tinbergen (1960), based on a theory originally proposed by von Uexküll (1934/1957). Tinbergen studied the densities of cryptic insect prey in the diet of small birds living in pine woodland. Prey were consumed less frequently than expected by chance when their numbers were relatively low and more often than expected by chance when their numbers were high. As a consequence, relatively small increases in prey density could result in large increases in predation, as the number of prey of a particular type appeared to cross some sort of threshold beyond which the predators "switched on" to that prey type.

Tinbergen (1960) proposed that the probability of detecting a prey item was a function of the recent previous experience of the predator. A series of successive detections of the same prey type, he reasoned, would serve to 
activate a representation of the prey item in the predator's nervous system. Subsequent search would then be guided by particular features of the representation, increasing the predator's efficiency at detecting that prey type. If predators possessed such a mechanism, then when the density of a particular prey type reached a high enough level relative to the density of other prey types, that prey type would be more likely to be encountered several times in succession and subsequent detections of it would be enhanced. As a result, searching image would result in a sudden increase in predation, resembling the observed pattern.

Although Tinbergen's hypothesis was fully consistent with the observed relationship between prey density and predation, it quickly became apparent that a number of other behavioral mechanisms could also contribute to the effect (Krebs 1973). For example, if different prey types live in different microhabitats, and if predators tend to search most intensively within those microhabitats that had proved most profitable in the recent past, a similar relationship would be obtained. Indeed, there seems little doubt that Tinbergen's findings probably reflected a number of different population processes, and did not constitute unequivocal evidence in favor of searching image. Nonetheless, the cognitive complexity and evolutionary implications of the searching image hypothesis have attracted many investigators over the years, including both of the authors of this chapter.

The searching image hypothesis makes sense in terms of many aspects of the biology of cryptic prey. For example, the natural distribution of cryptic organisms is often highly dispersed (Sargent 1976), which could function to limit the chances of a predator's acquiring a searching image by making successive encounters with the same prey type less likely. Searching image could also account for the high degree of polymorphism found in the appearance of many cryptic prey, through the selective advantage provided to novel, rare forms. The effects of hunting by searching image could, thus, be of substantial biological importance. In addition, the searching image concept appears to provide an immediate link between psychology and ecology. That is, although the idea of the searching image was based on biological and ecological phenomena, it is closely related to psychological concepts, such as selective attention and feature-based visual search (Bond 1983; Blough 1991). Thus, it provides an excellent context for multidisciplinary studies of cognitive mechanisms.

However, testing the searching image hypothesis presents substantial methodological challenges. In its most rigorous form, the hypothesis requires measuring changes in the ability to detect a cryptic prey as a function of recent experience with that type of prey, while controlling for all other factors that may influence the detectability. At minimum, therefore, it demands a procedure that allows complete experimental control over the sequence of prey encounters experienced by a predator. Furthermore, if, as Tinbergen (1960) proposed, searching image formation is only important when the prey 
are cryptic, the procedure would have to allow a fairly realistic level of difficulty.

\section{The Operant Analog to Predatory Search}

Kamil was first introduced to Tinbergen's hypothesis and the challenges that it presents in the early 1970 s by a colleague, Ted Sargent, in the context of his studies of underwing moths of the genus Catocala (Sargent 1976). Underwing moths have brilliantly colored hind-wings, but their fore-wings are complex patterns of muted tones that closely resemble the bark on which the insects rest during the day. One of the primary predators on these cryptic moths during the daylight hours is the blue jay (Cyanocitta cristata), and, by happy coincidence, Kamil happened to have a laboratory population of handraised blue jays from a research program on complex learning in Corvidae (Kamil \& Mauldin 1987). The predator and the prey were available. And the question was most interesting: Would blue jays get better at detecting a particular type of cryptic Catocala moth if they encountered several of that type in succession? The problem was to come up with a technique for asking the question.

The issue was actively pondered and discussed for several months, until Kamil attended a departmental seminar about "concept formation" in pigeons (Herrnstein 1964, 1985). In this research, pigeons were presented with a large array of projected images, shown one at a time on a pecking key in an operant chamber. Some of the images contained an example of the "concept," for example, a tree, while others did not. The rule for the pigeon was that it received food if it pecked at the key when a tree was shown and no reward for pecking when no tree was present. The images were extremely variable in content and included many different trees of different species, in photos taken from many different angles and distances. Herrnstein found that pigeons learned this task well, pecking at images with trees with much higher probability then at images without trees. More important, they responded appropriately to new images, both with and without trees, which they had never seen before.

While concept learning was crucial to Herrnstein, the technique he used was the focus of Kamil's interest. The seminar gave rise to an astoundingly simple idea: substitute cryptic moths for trees and blue jays for pigeons, make a few changes in the responses required to more accurately reflect foraging behavior, and, voila, a technique that would allow direct and elegant testing of the searching image hypothesis. The use of projected images would allow visual detection of cryptic moths and make it easy to control the order of encounters with different prey types by controlling the sequence of the slides. 
Pietrewicz and Kamil (1977) took a camera and a set of dead moths into the woods and made a series of photographs of trees, some with moths and some without. For each image that contained a moth, there was an identical image without one, and the location of the moth within the image was randomized across the set of images. These images were then shown to the jays, one at a time, in an operant chamber that had a large rectangular pecking key, a small round pecking key, and a food cup mounted on one wall (Fig. 15.2).

We modified Herrnstein's contingencies to more closely approximate foraging behavior. Each day, each blue jay was tested for sixty-four trials, thirty-two with moths, and thirty-two without moths, in random order. During each trial, one slide was projected on the rectangular key. The bird could either peck at the moth or peck at a small round key located to one side of the large key. The contingencies are summarized in the table below. The results of a peck at the large key depended on whether the trial was "positive," that is, whether a moth was present in the projected image.

\begin{tabular}{ccc}
\hline \hline & "YES" RESPONSE & "NO" RESPONSE (PECK \\
& (PECK AT LARGE KEY) & SMALL GIVING-UP KEY) \\
\hline POSITIVE TRIAL & FOOD (10 S) FOLLOWED BY & 2-S DELAY (ITI) \\
(MOTH PRESENT) & $\begin{array}{l}\text { 2-S DELAY (ITI) } \\
\text { NEGATIVE TRIAL } \\
\text { (MOTH ABSENT) }\end{array}$ & $\begin{array}{c}\text { 30-S DELAY (ITI) - (penalty } \\
\text { for pecking an area with- } \\
\text { out prey) }\end{array}$ \\
\hline
\end{tabular}

Pecks to the large key on positive trials earned the bird a piece of mealworm. It was given ten seconds to eat the mealworm, followed by a twosecond delay to the beginning of the next trial. If there was no moth in the image, pecking at the image produced just a thirty-second delay before the start of the next trial. The results of a peck at the small round key always produced a two-second delay followed by the start of the next trial. Thus, from the jay's point of view, each trial was like a patch to be searched for a moth. If a moth was found, a "Yes" response (pecking at the moth image) resulted in a food reward. If no moth was found, then the jay could move to the next patch by making a "No" response. Attacking an image without a moth resulted in wasted time, as does attacking nonprey items in natural foraging. Saying "No" when a moth was actually present produced no special result. In nature, when a predator fails to detect a prey item, there is no signal that informs the predator of its mistake. 

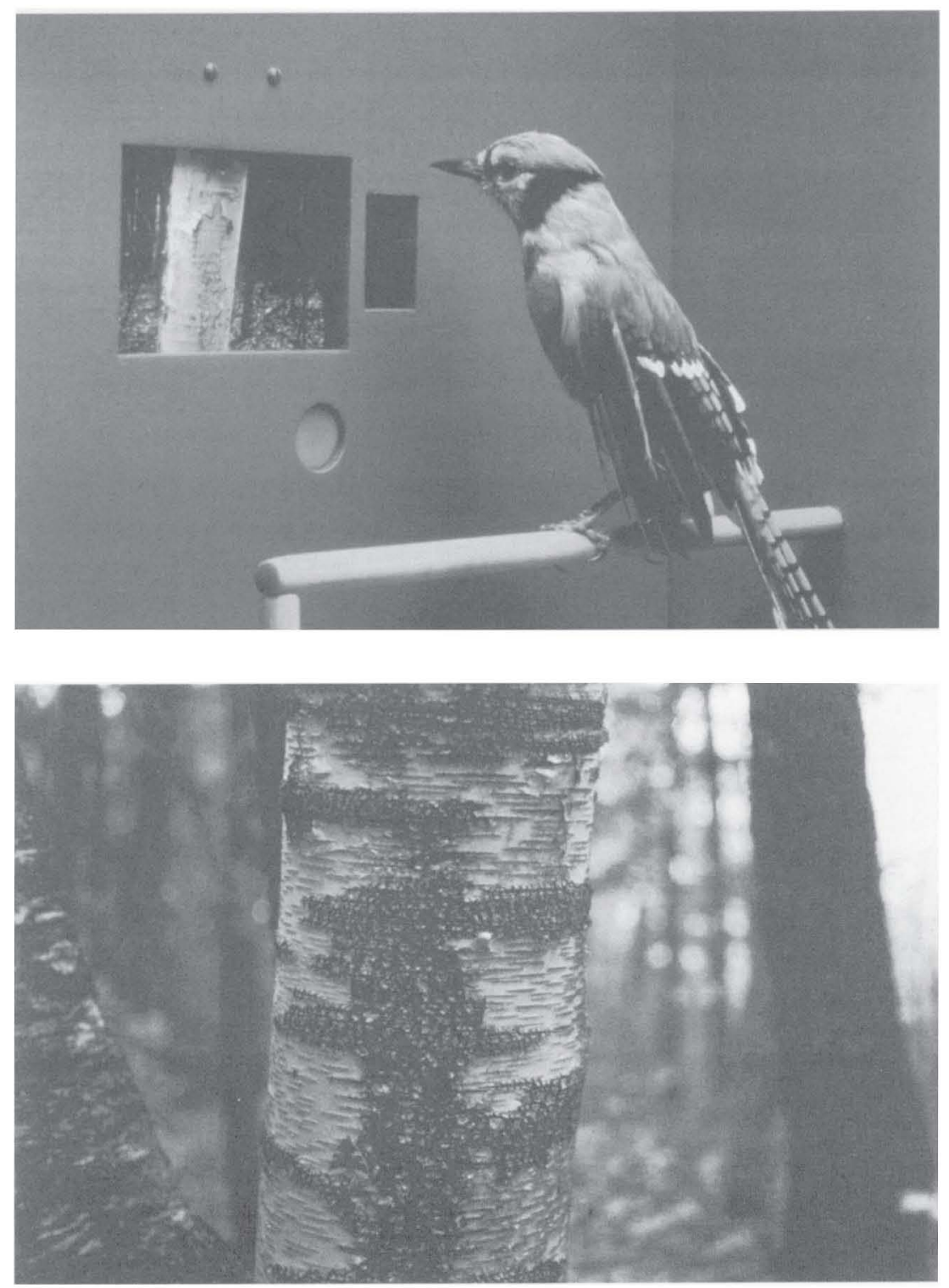

Figure 15.2. The top panel shows a blue jay in the test apparatus. The bottom panel shows an example of a cryptic $C$. relicta on a white birch tree. 


\section{Internal and External Validity}

Any attempt to construct a controlled experiment to investigate a natural phenomenon inevitably raises the issues of external and internal validity (Cook \& Campbell 1979; Kamil 1988). Internal validity refers to the extent to which a research design allows unambiguous attribution of cause and effect. That is, a study with high internal validity is well-controlled, so that if there is a difference between treatments, the difference can be ascribed to effects of the independent variable. External validity refers to the range of situations to which the results of the study can be generalized or applied. Obviously, any researcher would like each and every study to have both high internal and high external validity. Unfortunately, this is impossible. The steps required for high internal validity almost always lead to a reduction in external validity and vice versa (see Kamil 1988, for more detailed discussion).

The procedures developed by Pietrewicz and Kamil (1977) provide a good example of this trade-off. In order to control the appearance of the moths, we resorted to the use of photographic images. This allowed us to increase internal validity in several ways. For example, critical to testing Tinbergen's searching image hypothesis, it allowed control of the order of encounters with prey by controlling the order of slides in the projector. Thus, we could set up blocks of trials that were absolutely identical except for the order of the prey within the block. But this high level of internal validity came with a price. How could we know that the use of projected images (and all of the many other features of the operant procedures) had resulted in a situation in which the behavior of the jays was representative of behavior in natural situations?

The operant simulation appears logically reasonable. Consider a predator hunting for cryptic moths. The moths normally rest on tree trunks all day long, without moving, and press themselves down flat against the substrate, so a two-dimensional still image provides a reasonable visual approximation. Cryptic prey generally disperse, so that any given area is unlikely to contain more than one moth, and many areas will contain none. Thus the predator must go from patch to patch searching. In each patch it must search until it either finds a prey or decides to move on to the next patch. If it finds a moth it gets food; otherwise it merely expends time. If the predator attacks a nonfood item, it wastes additional time. These characteristics of the relationship between foraging behavior and its outcomes were present in our procedures. Thus there is a strong argument that we had constructed a reasonable simulation of hunting for highly dispersed, cryptic prey.

However, this is a very subjective judgment. Was there any way to empirically test the adequacy of these procedures, some kind of objective test of external validity? We accomplished this by testing hypotheses derived from 
detailed studies of the moths themselves (Sargent 1976). For example, each species of Catocala selects a specific substrate on which it prefers to rest. We reasoned that if our procedures were reasonable facsimiles of the real thing, the moths should be least detectable when presented on their speciesspecific substrates. So, Pietrewicz and Kamil (1977) took Catocala that differ in substrate preferences and tested them on several substrates. Each species tended to be least detectable on the type of tree on which they normally rest.

Another source of validation derives from an analysis of the type of search that the jays must use (Kamil et al. 1993), a type called exhaustive, self-terminating search. Consider the process of scanning a discrete area for the presence of a hard-to-find prey item. When a prey item is detected, it should be attacked immediately. However, it makes little sense to leave the patch until the whole area has been scanned. Thus, on the average, it should take longer to decide to leave an empty patch than to attack a prey item. This is also characteristic of the behavior of the jays in our simulation. Thus, we are reasonably confident that the operant procedures capture at least some of the important aspects of natural foraging for cryptic prey by visual predators. The next step was applying the operant procedures to the searching image hypothesis.

\section{Testing the Searching Image Hypothesis}

Tinbergen specified that a specific experience, encountering a single, cryptic prey type several times in succession, should produce a specific effect, an improvement in the predator's ability to detect that prey type. In order to test the hypothesis properly, it is therefore necessary to create conditions that are identical in every respect except that in one condition the prey have been encountered in succession while in the other they have been encountered in random order. Furthermore, conditions of the experiment must be such that any change in the capture of prey must be reasonably thought to be due to a change in the predator's ability to detect the prey.

It is not easy to meet this pair of requirements, and many studies have failed to control for one or another factor (reviewed by Krebs 1973). For example, one common design is to expose the predator to just one type of prey for some time, then give it that type plus a new type. In these conditions the predator will usually take the type to which it was preexposed. But clearly this could be caused by many factors other than changes in detection. Simple familiarity could lead to a preference; the predator might detect all of the prey, but prefer to consume the familiar one. Detection of the prey needs to be dissociated from consumption. The operant technique of Pietrewicz and Kamil does, however, meet the requirements. It separates detection from consumption: the birds detect the moths in the images, but eat pieces of 
mealworm. It allows complete control over the order in which the prey types are presented to the predator. And it is clearly a detection task.

To test Tinbergen's (1960) hypothesis, Pietrewicz and Kamil $(1979,1981)$ tested each of a group of jays daily with a series of images, half of which contained moths. Two types of moths appeared equally often: $C$. relicta on birch and $C$. retecta on oak (as in 2). During each session, an experimental block of sixteen trials, half positive and half negative, in random order, occurred. One-third of these blocks were "nonruns," and included four instances each of $C$. relicta and $C$. retecta, in random order (and eight slides without moths). The other two-thirds were "runs" during which all eight of the moths in the set were either $C$. relicta or $C$. retecta. Thus the run and nonrun conditions were identical except for the order of encounter with the prey types. While nonruns exposed the jays to both prey types in random order, runs exposed them to eight consecutive encounters with a single prey type. The results were unequivocal (Fig. 15.3). Performance improved during run blocks but not during nonruns. This data provided the first methodologically sound test of the searching image hypothesis. Subsequent experiments with jays (e.g., Kono et al. 1998) and with pigeons searching for cryptic grains (Bond \& Riley 1991; Langley 1996) have replicated these basic findings. These experiments demonstrate how operant techniques developed by psychologists can be used to evaluate biological hypotheses.

\section{Development of the Collaboration}

The authors were both in the Psychology Department at Berkeley during the 1976-77 academic year. We got to know each other professionally, discovering many mutual research interests, particularly a general interest in studying cognition in meaningful ecological contexts as well as a more specific interest in searching image. Bond had come to searching image through a wholly different route. During a graduate zoology seminar in 1974, he realized that for apostatic selection actually to stabilize a prey population, it must be exhibited as a sustained bias in favor of more abundant prey types, even when the appearance of all potential prey was thoroughly familiar to the predator. Most of the experimental evidence that existed at that time did not effectively address this issue, since the designs generally involved presenting birds with two prey that differed in their familiarity. If learning to detect a novel prey were all that was involved, apostatic selection would require that predators rapidly forget the appearance of rarer prey items, something that seemed highly unlikely.

Bond put together a postdoctoral proposal to explore this issue using pigeons searching for cryptic grain. The choice of species was dictated by the decision to cross over from biology to psychology for this work: pigeons were what they had to work with in Donald Riley's comparative psychology 


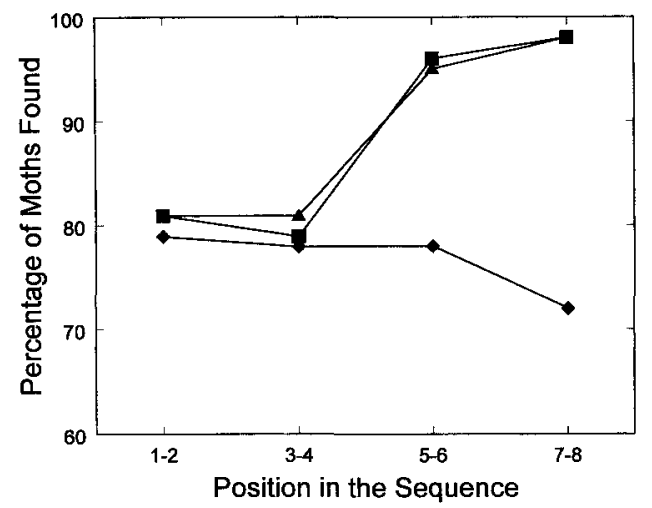

Figure 15.3. Detection of moths improved when several of the same type $(C$. relicta or $C$. retecta) were encountered in a row (run condition) than when they were presented in random order (nonrun condition). Redrawn from Pietrewicz and Kamil (1979).

laboratory. But the choice of organism, in turn, determined the experimental approach. Pigeons feed on the ground on scattered grains, and different types of grain are generally intermixed in a given area. Thus the birds were shown trays containing plastic-coated gravel and a random scattering of grains of two different types, beans and wheat. Unlike Kamil's design, which involved presenting the stimuli one at a time and regulating the bird's attentional state by modifying the sequence of presentation, the pigeon experiments presented all grain stimuli simultaneously, and the sequence of grains taken was a function of the bird's cognitive processes.

Pigeons showed a natural bias in favor of more abundant grain types when the food was presented on a cryptic background, even when the birds were thoroughly familiar with all grain types (Bond 1983). The bias was lower when the stimuli were harder to detect, and it was reversed when the grains were presented on a uniform gray background. The effect was large and robust, clearly implicating a process that would be important in the realworld ecology of the species. The problem with this natural grain preparation was that it was very difficult to manipulate the relationship between the background and the grains, and it was not feasible to record responses to individual grains to obtain direct measures of speed and accuracy of response.

In 1985, Bond and Riley returned to the issue of searching image in pigeons, using the Pietrewicz and Kamil (1979) operant approach. Photographs of cryptic grains were back-projected on a ground-glass pigeon key, and the birds were required to peck grains if they were present in the image. If the image was of gravel alone, the birds were trained to peck an advance key. The experiment proved very difficult to conduct. Pigeons are reluctant to peck a key that terminates the trial without a food reward and it proved necessary to provide food rewards for correct responses to nongrain stimuli. This, in turn, required careful titration of reward rates to avoid response biases. It is a good example of the dangers inherent in taking a design that 
works well for one species and porting it to another, ecologically unrelated organism. Although Bond and Riley (1991) did find a significant run effect, the operant approach to the detection of cryptic food was clearly problematic with pigeons. More recent operant investigations of searching image in pigeons have commonly used a different design, in which target stimuli are present in all displays and the searching image effect is detected solely in terms of response time (e.g., Blough 1991; Langley 1996). By 1989, Bond had been convinced that there was nothing more to be learned from such inflexible and complex experimental designs and had shifted his focus to social behavior. Aside from collaborating on one final attempt to improve on the natural grains preparation (Langley et al. 1996), he was effectively out of the searching image business.

Kamil and his lab continued to exploit the operant procedure with blue jays to investigate searching image (Pietrewicz \& Kamil 1979, 1981; Kono et al. 1998), as well as a variety of other phenomena. One series of studies used the procedure to emulate foraging in patches of varying quality (Kamil et al. 1985; Kamil et al. 1988; Kamil et al. 1993). Another study (Olson et al., unpublished; Endler 1991) varied the level of prey crypticity by photographing moths on trees whose bark varied in complexity. As complexity increased, the match between the appearance of the bark and the appearance of the moth also tended to increase, which had several effects on the jays' behavior. With higher crypticity, the birds became less accurate, but they also modulated their speed of response, taking longer to decide when confronted with more complex trees.

Despite these successes, Kamil also found that the use of images of real prey items imposed severe methodological limitations. The presentation of photographic images to birds was technically cumbersome, and the array of possible stimulus displays necessarily limited. But the most restrictive feature of these existing techniques was that they were essentially static and unidirectional. The researcher determined the degree of crypticity, the proportions of different prey types, and the order of stimulus presentation, and the birds simply responded to the imposed treatments. The evolutionary interaction between predators and prey involves a dynamic, reciprocal interaction between prey appearance and abundance and predator perception that was wholly lacking in these studies. The question of how the psychology of predators might affect the evolution of their prey (Guilford 1990) appeared wholly out of reach.

And then, coincidentally, both authors ended up at the University of Nebraska. Given our previous contacts and separate work on searching images, we naturally began to explore working together on the detection of cryptic prey. The discussions centered around the lovely experiments that could be done if we could devise an artificial prey that emulated the complexity and crypticity of real moths and yet was amenable to systematic dimensional variation. But the discussions were merely idle speculation until Kamil re- 
turned from a vacation in England with the germ of the crucial idea. While visiting at Cambridge, Kamil had attended a dinner with friends, which led to an invitation to visit Nick Mackintosh's operant lab. The invitation was initially declined because Kamil's trip (with spouse) was strictly vacation. But Nick mentioned that one of his students, Kate Plaisted, was doing research on searching image in pigeons. A quick visit was arranged, in the course of which Kamil saw the stimuli that Plaisted had developed (Plaisted 1997; Plaisted \& Mackintosh 1995). Plaisted's targets were black-and-white checkerboards displayed on a background of black-and-white squares. Crypticity was manipulated by varying the proportions of different sized patches of black in the background.

On returning to Nebraska, Kamil and his newfound enthusiasm for the checkerboard pattern led to a series of crucial brain-storming sessions. Plaisted's checkerboards appeared to lack the requisite dimensional complexity and were probably insufficiently cryptic to fool blue jays, but the basic idea of stimuli consisting of coarse arrangements of pixels was very attractive. Bond had extensive experience with digital graphics and multimedia programming, and he felt that it might be fairly simple to scan images of Catocala, convert them to a 64-level gray scale, and reduce them to coarsely digitized $16 \times 16$ pixel squares. The resulting digital prey were then presented on backgrounds of a complex texture that was similar in brightness and grain to the patterns on the moths. By varying the match between the distributions of gray-scale values in the moths and the background, the degree of crypticity could be controlled with great sensitivity (Fig. 15.4). Detecting these digital moths was comparably difficult, at least for human observers, to finding real moths in photographic images, but as was the case with the original use of photographic images (Pietrewicz \& Kamil 1977), a formal test of external validity was required.

\section{Validation of the Digital Moth Approach}

One purpose of our initial experiment, therefore, was to compare the behavior of jays searching for digital moths with that shown by jays searching photographic images for real moths (Bond \& Kamil 1999). We trained the birds to detect three distinctive digital moths presented on backgrounds of varying crypticity. As the crypticity increased, detection accuracy decreased and response speed increased. We also found much longer latencies to say "No" on trials without moths than to say "Yes" on trials with moths, suggesting an exhaustive, self-terminating search of the display. Both of these features were also characteristic of the behavior of jays searching for real moths.

Jays tested with images of real moths also showed searching image effects, so we used a design very similar to the original Pietrewicz and Kamil (1979) study to examine the effects of changes in the trial sequence. Over the course of the experiment, each bird received 180 "treatment blocks" of 


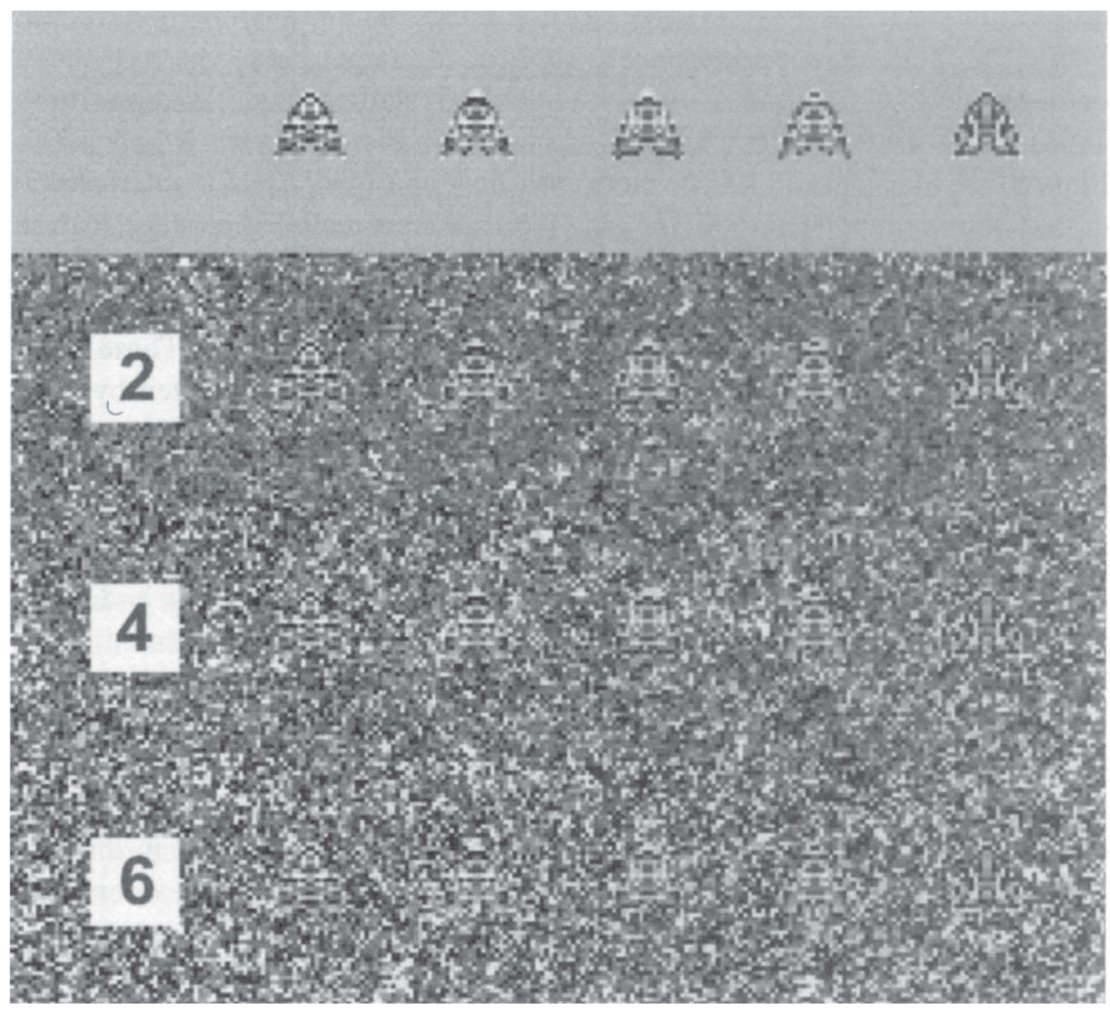

Figure 15.4. Five types of digital moths used in these experiments presented against backgrounds of three levels of crypticity to illustrate the difficulty of the detection task. When projected on the computer monitor, the moths were about 6 millimeters high.

16 trials, 8 containing digital moths and 8 without (in random order). Fortyfive of these were control blocks, containing all 3 prey types in random order. The other 135 were run blocks, containing 8 prey of the same type (45 for type I, 45 for type II, and 45 for type III). The results were clear-cut: as with photographic images, a searching image effect was obtained.

The most important finding of this experiment, however, concerned one of the earliest predictions of searching image theory, the idea that a searching image for one prey type actively interferes with detection of prey of a disparate appearance (von Uexküll 1934/1957). The prediction is now generally interpreted in terms of selective attention. Because organisms have only a limited ability to process information, selective attention to one specific stimulus or modality has commonly been seen as requiring a reduction in attending to alternatives (Kahneman 1973). Thus, a bird with a searching image for one prey type would experience not only an improvement in the ability to detect that prey, but also a decreased ability to detect alternative prey items. The concept is attractive and easily understood, but demonstra- 
tion of interference effects in searching image had proven very difficult. While the facilitative effects on detection of the target prey type have been demonstrated in a number of well-controlled studies (e.g., Blough 1989, 1991; Bond \& Riley 1991; Kono et al. 1998; Pietrewicz \& Kamil 1979; Plaisted \& Mackintosh 1995), there was no good evidence for interference effects during cryptic prey detection. We therefore included another feature in our experimental design to test for interference effects. Each run or nonrun treatment block was followed by a four-trial probe block, containing two positives of one of the three digital moths and two negatives. These were arranged so that each type of run block was followed equally often by each type of probe.

The issue under test was whether the jays were poorer at detecting moths in probes following a run of a different prey type than in probes following a nonrun. To examine this question, we measured the effect of the run in terms of the difference in accuracy between probe trials following runs and those following nonruns. Detection of the same prey type that was presented in the run was facilitated in the probes, a continuation of the searching image effect. The effects of runs of a different prey type on probe accuracy depended on the relative levels of crypticity, however. When the prey type in the probe trials was more conspicuous than that used in the previous run, there was no effect. But when the probe type was more cryptic than that used in the run, detection accuracy was significantly reduced, providing clear evidence of interference. Similarly asymmetrical interference effects have been seen in other studies, suggesting that it may be a general phenomenon (Blough 1989, 1992; Bond \& Riley 1991; Reid \& Shettleworth 1992; Lamb 1988).

Finally, we used the data from this experiment to test an alternative hypothesis, the suggestion that searching image effects are consequences, not of shifts in selective attention, but of selective forgetting of short-term memory traces (Plaisted 1997). Plaisted pointed out that the mean time interval between successive appearances of the same prey type was shorter during a run of a single prey type then during a random series of two or more prey types. Thus, she argued, increased forgetting during nonruns could account for the relatively higher levels of detection during runs. She then provided evidence that detection was improved when the amount of time since the last target of the same type was reduced, even in nonrun blocks (Plaisted 1997).

Although this was a tenable hypothesis, several considerations suggested that mnemonic effects were unlikely to provide a complete account of searching image. The time intervals Plaisted used were relatively short, generally well less than a minute, and experiments with pigeons feeding on natural grains had found no decrease in a response bias to the most abundant grain type over intervals less than three minutes (Langley et al. 1995). Furthermore, Plaisted's pigeons could not make a patch departure decision; they were not reinforced for pecking at displays without targets. We therefore thought it important to test Plaisted's hypothesis in our experimental para- 
digm. We examined the effects of the time interval between presentations of the same prey type, confining our analysis to cases in which the time interval was less than three minutes and tested to see whether it provided a superior account of the results. We found that the interval between successive presentations of the same prey type had no effect on the probability of detection and that response time actually decreased as the time interval increased. These results, combined with the interference effects we discovered, are clearly contrary to Plaisted's hypothesis.

\section{Virtual Ecology}

Reassured that our digital moths replicated earlier work with images of real moths, we undertook a study that broke new ground, taking advantage of our increased ability to control and manipulate the stimuli. One strength of the digital moths is that they do not limit the number of different stimuli that can be presented to the birds. Novel backgrounds can be generated at will. The placement of the moths in the image need not be fixed. It can be determined randomly at the time of presentation. There was, thus, no concern that specific images might differ in their inherent difficulty level or that the birds might memorize the moth's location in particular images, and there was no need to control the particular sequence of stimuli being displayed. This opened the door to "virtual ecology," in which populations of digital moths are maintained in the computer as lists of individuals, and the impact of the predator's behavior on prey population dynamics is played out directly.

Our first virtual ecology study (Bond \& Kamil 1998) tested the effects of apostatic selection on the maintenance of a prey polymorphism. We created a virtual prey population of 240 individual digital moths, 80 of each of 3 distinctive morphs, and exposed them to predation by 6 blue jays. The moths the jays detected were considered "killed" and were removed from the population. Those that were overlooked were allowed to breed (asexually), bringing the population back up to 240 for the following day. Each day thus constituted a generation, and our only experimental intervention was to set the initial numbers of the 3 morphs. No matter what initial conditions were imposed, however, the relative numbers of the 3 morphs rapidly approached a set of characteristic values. One morph was somewhat more cryptic than the others, so it stabilized at a higher population level. We perturbed this system several times, drawing down the abundance of the most common morph and raising that of one of the less abundant. Each time, the system returned to the same equilibrium levels (Fig. 15.5). Subsequent analysis demonstrated that the equilibrium was a result of negative feedback between prey abundance and prey detectability. The more common any of the prey types became, the more likely it was to be detected and removed from the population. 


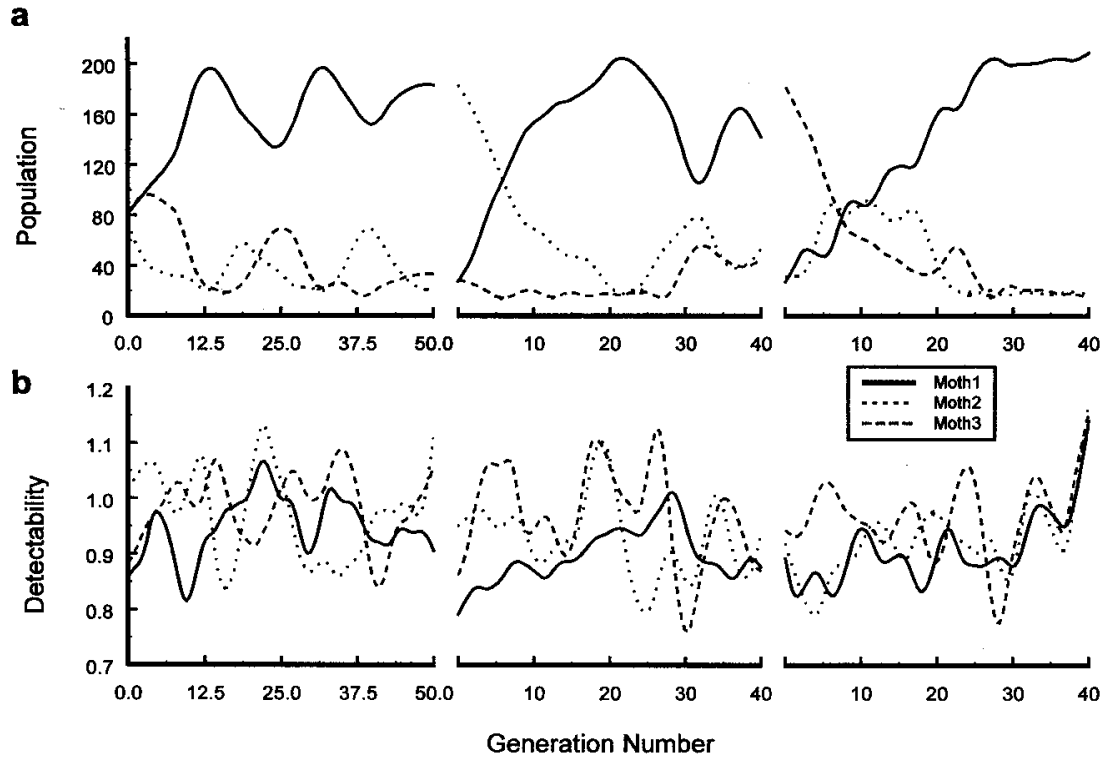

Figure 15.5. Population numbers of three species of digital moths in three successive replications of the virtual prey procedure. Curves were smoothed with weighted least squares, using an eight-generation window.

We then tested the effects of apostatic selection on novel morphs. In theory, since a new morph will initially be present in low numbers, and since predators will have had no prior experience with them, apostatic selection should favor rare novel forms. In our first introduction of a novel morph, the new prey type increased in abundance until the jays caught on to its presence and began to search for it in earnest. Its numbers subsequently declined until it reached an equilibrium level comparable to that of two of the original morphs. In the second iteration, the new type was extremely cryptic. Only two of the six jays learned to detect it, even after fifty generations. As a result, it quickly came to dominate the population, and the other morphs would have been driven to extinction if we had not brought their numbers up to a minimum (five) with each new generation. This result illustrates the power of selection in virtual ecology: a new morph introduced at very low levels can, in a short time, rise almost to fixation, driving out less cryptic variants.

\section{Virtual Genetics}

The wing of a digital moth consists of seventy-five unique gray-scale pixels on one wing, replicated on the opposite wing. Given this relatively simple phenotype, Bond saw that it was feasible to eliminate the constraint of having uniform appearance within a moth type and endow digital moths with a 
virtual genetics that would determine the appearance of their wings. The genetic algorithm he developed was largely based on current understanding of the control of lepidopteran wing patterns (Robinson 1971; Nijhout 1991, 1996; Brakefield et al. 1996). We did not attempt to simulate lepidopteran genetics in full detail, but, rather, constructed a simpler system that nevertheless remains true to many of its salient features. The most significant simplification we adopted is that the moth phenotype is generated from a single, haploid chromosome, a string 117 bytes in length, in which each byte constitutes a gene. The relationship between gene and phenotype is not one-to-one, however. As in real moths, phenotypic characters are polygenic. The wing pattern of a digital moth is encoded by eighteen loci, each consisting of five genes which, taken together, define an elliptical wing patch. The location, eccentricity, orientation, extent, and peak intensity of each patch are each determined by the value of a separate gene within each locus. The intensity of each pixel in the phenotype is thus affected by several overlapping patches, which interact additively. One attractive feature of this design is that it incorporates redundancy in the genome that helps to maintain the level of genetic variance in the population, in spite of the absence of heterozygosity.

In this final stage of the development of our technique, our population of digital prey could now reproduce sexually. Their wing patterns are transmitted to their offspring, but because of recombination and mutation, the offspring are imperfect copies of their parents. And this enables us to ask questions, not just about the maintenance of prey crypticity and polymorphism, but about its evolutionary origins. Initial experiments on our virtual moth genome suggest that it is ideally suited for investigating natural selection. In particular, a random selection from the $2^{936}$ possible genotypes produces a population that is strikingly variable in appearance, but all of the phenotypes still appear reasonably moth-like (Fig. 15.6). This is essential, because the jays are trained to treat any of these objects as a potential prey item.

Equally essential, the genome is responsive to selective pressure. We demonstrated this by presenting blue jays with an initially random population of two hundred digital moths displayed on a background of moderate crypticity. Prey items that are overlooked during their exposure to the predator have three times as great a probability of being allowed to breed as those that are discovered. After twenty generations, two effects of selection by the jays can be seen. The population of moths became significantly darker. The moths also became more cryptic to the jays. Although this may not be obvious to human eyes looking at the population (Fig. 15.7), the moths in the twentieth generation take longer to detect than the moths in the first generation. These results confirm the role of predation in determining appearance of the moths. To extend this work, we are currently developing a series of experiments to test the effects of predator psychology on the evolution of cryptic prey polymorphism. The experiments will be unique in combining a simulated prey population (that nevertheless retains many of the critical features of real organisms) with a laboratory population of real predators. Although these 
P1 Generation: Initial Randon Popn

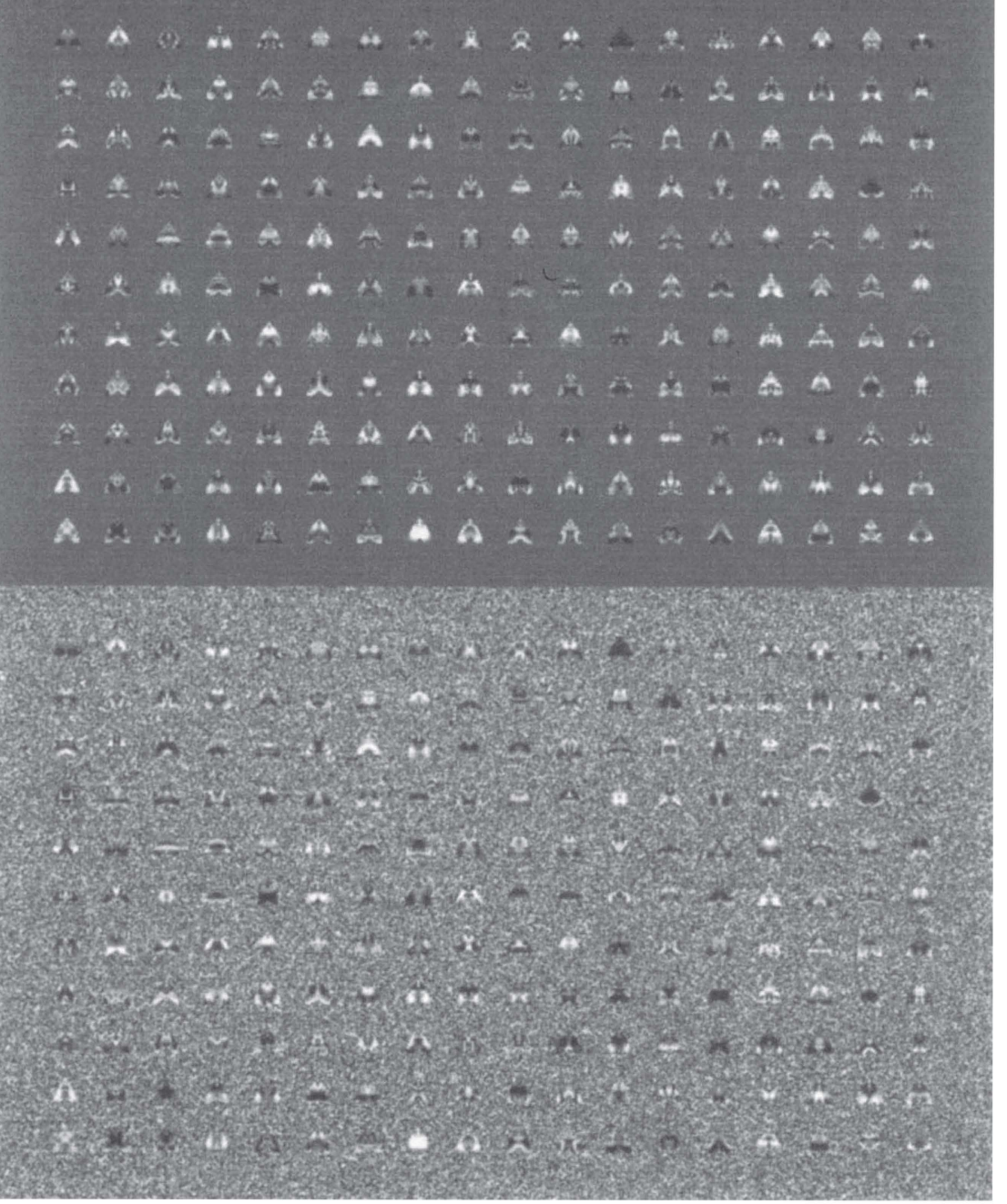

Figure 15.6. A population of digital moths created by randomly sampling the population of possible digital moth genomes 198 times. The moths are shown on both a plain gray background and a patterned background.

predators cannot be considered "evolutionarily naive" (Guilford 1990; Schuler \& Roper 1992), our technique will enable us to explore these questions under conditions in which predator choice and prey appearance are dynamically related and, for the first time, to test directly theoretical predictions about the course of predator/prey evolution. 
F20 Generation: Selection on $\mathrm{Bkg} 3$
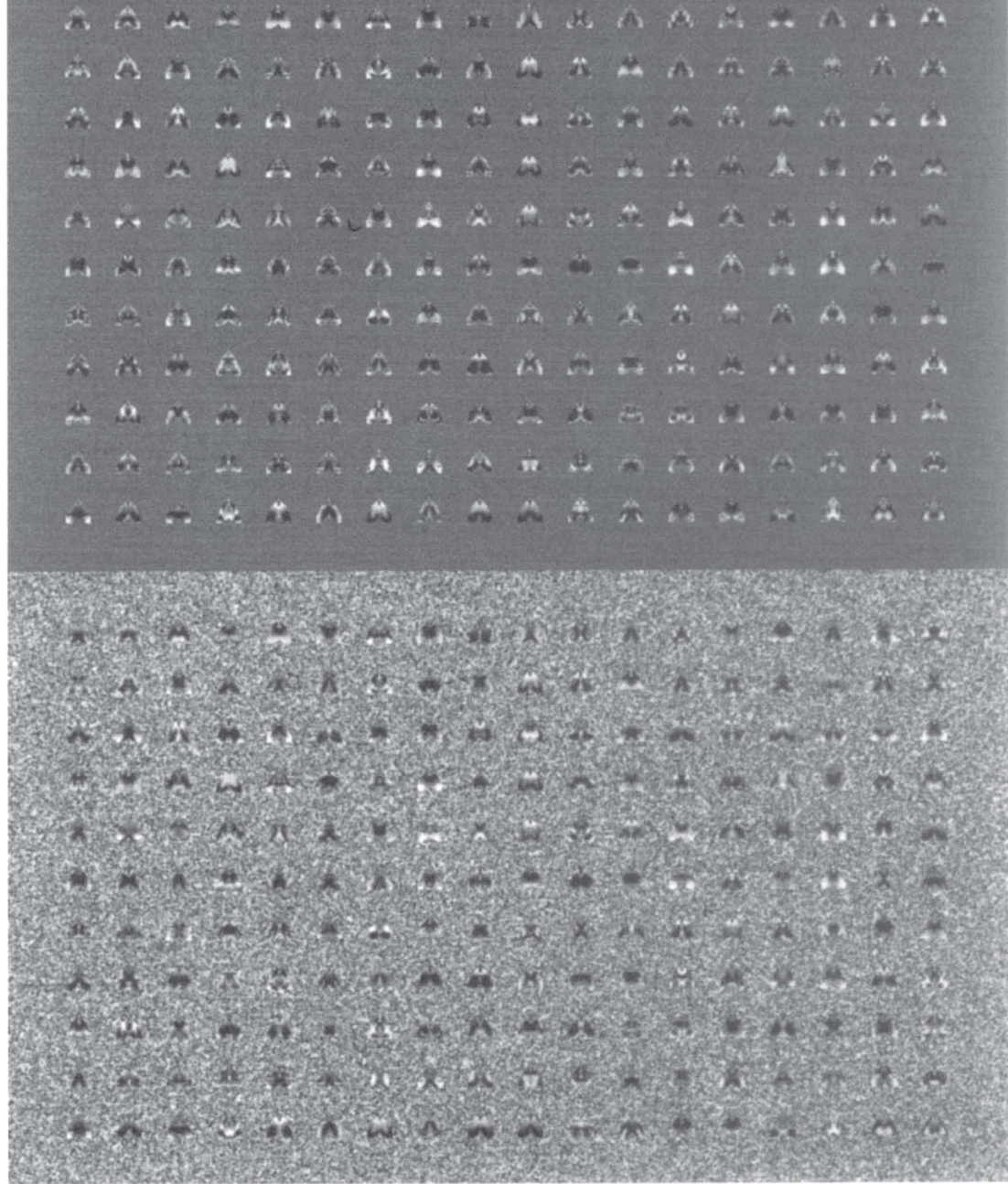

Figure 15.7. The same population of moths as shown in Figure 15.6, after twenty generations of selection by blue jays.

\section{Coincidence and Insight in the Evolution of Virtual Ecology}

Virtual ecology blends ideas and methods from many disciplines, including operant psychology, behavioral ecology, population dynamics, and evolutionary computing. We could not have developed the technique if we had limited ourselves to just biology or psychology. This synthesis has resulted 
in an exciting, innovative procedure for the experimental study of evolutionary dynamics. Adaptationist stories are the bane of behavioral and evolutionary ecology, but in many cases the stories are actually hypotheses, hypotheses that have simply been inaccessible to empirical test. Virtual ecology provides a methodology that can be used to begin to explore these hypotheses under rigorous, realistic, and repeatable circumstances. As an example, consider the hypothesis that background heterogeneity may facilitate the evolution of polymorphisms in cryptic prey. Virtual ecology can be used to test this idea simply by subjecting different populations of moths to selective predation by jays under different conditions of background heterogeneity. We believe that virtual ecology can probably be adapted to investigate any circumstance in which the detection, selection, and/or choice among signals emanating from an organism affects the evolution of those signals. And it was only made feasible by the synthesis of ideas across traditional disciplinary boundaries.

The element of coincidence in the history of this research is characteristic of many developments in science. Experimental techniques evolve opportunistically, seldom being driven by the ideas of a single researcher working in isolation from the rest of the field. Would the procedure ever have developed to its current form if Herrnstein hadn't given that seminar or if Kamil hadn't had dinner with Mackintosh or if the authors had not both ended up at the same university? As is true of organic evolution, the evolution of an idea takes paths that are not readily repeatable. Chance plays a major role. Should this be taken to mean that an aspiring researcher should sit back and wait for lightning to strike? Absolutely not! There are two morals to draw: (1) Be alert and attentive to possibilities that arise. Chance favors the prepared mind. (2) Maximize your chances. Increase the probability of novel developments by exposing yourself to as broad a variety of ideas and facts as possible. Read, listen, and be prepared for the idea when it happens. And be sure not to allow disciplinary boundaries to constrain your thinking.

\section{Acknowledgments}

The preparation of this chapter and the research reported in it were supported by grants from the National Science Foundation.

\section{References}

Allen JA, 1988. Frequency-dependent selection by predators. Phil Trans R Soc Lond B 319:485-503.

Bates HW, 1862. Contributions to an insect fauna of the Amazon valley (Lepidoptera: Heliconidae). Trans Linn Soc Lond 23:495-566. 
Blough PM, 1989. Attentional priming and search images in pigeons. J Exp Psychol: Anim Behav Proc 15:211-223.

Blough PM, 1991. Selective attention and search images in pigeons. J Exp Psychol: Anim Behav Proc 17:292-298.

Blough PM, 1992. Detectability and choice during visual search: joint effects of sequential priming and discriminability. Anim Learn Behav 20:293-300.

Bond $\mathrm{AB}, 1983$. Visual search and selection of natural stimuli in the pigeon: the attention threshold hypothesis. J Exp Psychol: Anim Behav Proc 9:292-306.

Bond AB, Kamil AC, 1998. Apostatic selection by blue jays produces balanced polymorphism in virtual prey. Nature 395:594-596.

Bond $\mathrm{AB}$, Kamil $\mathrm{AC}$, in press. Searching image in blue jays: facilitation and interference in sequential priming. Anim Learn Behav.

Bond AB, Riley DA, 1991. Searching image in the pigeon: a test of three hypothetical mechanisms. Ethology 87:203-224.

Brakefield PM, Gates J, Keyes D, Kesbeke F, Wijngaarden PJ, Amonteiro A, French V, Carroll SB, 1996. Development, plasticity and evolution of butterfly eyespot patterns. Nature 384:236-242.

Cook, TD, Campbell, DT, 1979. Quasi-experimentation: design and analysis issues for field settings. Chicago: Rand McNally.

Darwin C, 1871. The descent of man and selection in relation to sex (2nd ed.). London: John Murray.

Endler JA, 1991. Interaction between predators and prey. In: Behavioural ecology: an evolutionary approach (Krebs JR, Davies NB, eds). Oxford: Blackwell Scientific; 169-196.

Guilford T, 1990. The evolution of aposematism. In: Insect defenses: adaptive mechanisms and strategies of prey and predators (Evans DL, Schmidt JO, eds). Albany: SUNY Press; 23-61.

Kahneman D, 1973. Attention and effort. Englewood Cliffs, NJ: Prentice-Hall.

Kamil, AC, 1988. A synthetic approach to the study of animal intelligence. In: Comparative perspectives in modern psychology: Nebraska Symposium on Motivation, Vol. 35 (Leger DW, ed). Lincoln: University of Nebraska Press; 230-257.

Kamil AC, Lindstrom F, Peters J, 1985. Foraging for cryptic prey by blue jays. I: The effects of travel time. Anim Behav 33:1068-1079.

Kamil AC, Mauldin JE, 1987. A comparative-ecological approach to the study of learning. In: Evolution and learning (Bolles RC, Beecher MD, eds). Hillsdale, NJ: Erlbaum; 117-133.

Kamil AC, Misthal RL, Stephens DW, 1993. Failure of simple optimal foraging models to predict residence time when patch quality is uncertain. Behav Ecol 4:350-363.

Kamil AC, Yoerg SI, Clements KC, 1988. Rules to leave by: patch departure in foraging blue jays. Anim Behav 36:843-853.

Kono H, Reid PJ, Kamil AC, 1998. The effect of background cuing on prey detection. Anim Behav 56:963-972.

Krebs JR, 1973. Behavioral aspects of predation In: Perspectives in ethology, vol. 1 (Bateson PPG, Klopfer PH, eds). New York: Plenum Press.

Lamb MR, 1988. Selective attention: effects of cuing on the processing of different types of compound stimuli. J Exp Psychol: Anim Behav Proc 14:96-104. 
Langley CM, 1996. Search images: selective attention to specific visual features of prey. J Exp Psychol: Anim Behav Proc 22:152-163.

Langley CM, Riley DA, Bond AB, Goel N, 1995. Visual search for natural grains in pigeons: search images and selective attention. J Exp Psychol: Anim Behav Proc 22:139-151.

Nijhout HF, 1991. The development and evolution of butterfly wing patterns. Washington, DC: Smithsonian Institution.

Nijhout HF, 1996. Focus on butterfly eyespot development. Nature 384:209-210.

Oaten A, Pearce EM , Smyth MEB, 1975. Batesian mimicry and signal detection theory. Bull Math Biol 37:367-387.

Pietrewicz AT, Kamil AC, 1977. Visual detection of cryptic prey by blue jays (Cyanocitta cristata). Science 195:580-582.

Pietrewicz AT, Kamil AC, 1979. Search image formation in the blue jay (Cyanocitta cristata). Science 204:1332-1333.

Pietrewicz, AT, Kamil AC, 1981. Search images and the detection of cryptic prey: an operant approach. In: Foraging behavior: ecological, ethological, and psychological approaches (Kamil AC, Sargent TD, eds). New York: Garland Press.

Plaisted K, 1997. The effect of interstimulus interval on the discrimination of cryptic targets. J Exp Psychol: Anim Behav Proc 23:248-259.

Plaisted KC, Mackintosh NJ, 1995. Visual search for cryptic stimuli in pigeons: implications for the search image and search rate hypotheses. Anim Behav 50:12191232.

Poulton EB, 1890. The colours of animals: their meaning and use, especially considered in the case of insects. New York: Appleton.

Reid PJ, Shettleworth SJ, 1992. Detection of cryptic prey: search image or search rate? J Exp Psychol: Anim Behav Proc 18:273-286.

Robinson R, 1971. Lepidopteran genetics. Oxford: Pergamon.

Sargent TD, 1976. Legion of night: the underwing moths. Amherst: University of Massachusetts Press.

Schuler W, Roper TJ, 1992. Responses to warning coloration in avian predators. Adv Study Behav 21:111-146.

Tinbergen L, 1960. The natural control of insects in pine woods. I: Factors influencing the intensity of predation by songbirds Archives Néerlandaises de Zoologie 13:265-343.

von Uexküll J, 1957. A stroll through the worlds of animals and men In: Instinctive behavior (Schiller CH, ed). New York: International Universities Press; 5-80. (Original work published 1934).

Wallace AR, 1891. Darwinism: an exposition of the theory of natural selection with some of its applications. London: Macmillan. 